\title{
Biologic importance and prognostic significance of selected clinicopathological parameters in patients with oral and oropharyngeal squamous cell carcinoma, with emphasis on smoking, protein p16 $^{\text {INK4a }}$ expression, and HPV status
}

\author{
J. LACO ${ }^{1, *}$, J. NEKVINDOVA ${ }^{2}$, V. NOVAKOVA ${ }^{3}$, P. CELAKOVSKY ${ }^{4}$, H. DOLEZALOVA ${ }^{3}$, L. TUCEK ${ }^{3}$, H. VOSMIKOVA ${ }^{2}$, M. VOSMIK ${ }^{5}$, \\ T. NESKUDLOVA ${ }^{5}$, E. CERMAKOVA ${ }^{6}$, M. HACOVA 7 , F. A. SOBANDE ${ }^{1}$, A. RYSKA ${ }^{1}$
}

${ }^{1}$ The Fingerland Department of Pathology; ${ }^{2}$ Institute of Clinical Biochemistry and Diagnostics; ${ }^{3}$ Department of Dentistry; ${ }^{4}$ Department of Otorhinolaryngology and Head and Neck Surgery; ${ }^{5}$ Department of Oncology and Radiotherapy, Charles University Faculty of Medicine and Faculty Hospital in Hradec Kralove, Czech Republic; ${ }^{6}$ Computer Technology Center, Charles University Faculty of Medicine in Hradec Kralove, Czech Republic; ${ }^{7}$ Department of Pathological Anatomy, Regional Hospital Pardubice, Czech Republic

${ }^{*}$ Correspondence: lacoj@lfhk.cuni.cz

Received December 2, 2011 / Accepted February 1, 2012

\begin{abstract}
The aim of this study is to evaluate the biologic importance and prognostic significance of selected clinicopathological parameters in patients with oral (OSCC) and oropharyngeal (OPSCC) squamous cell carcinoma, with emphasis on smoking, protein $\mathrm{p} 16^{\mathrm{INK} 4 \mathrm{a}}(\mathrm{p} 16)$ expression, and human papillomavirus (HPV) status.

The study sample consisted of 48 patients with OSCC and 44 patients with OPSCC. Half of the patients were nonsmokers and the other half were gender-, age- and tumor localization-matched smokers.

p16 expression was detected in 17/48 (35\%) OSCCs and in 36/44 (82\%) OPSCCs and HPV DNA was present in 7/48 (15\%) OSCCs and in 35/44 (80\%) OPSCCs. The sensitivity and specificity of p16 expression for HPV DNA presence were 0.74 and 0.88 , respectively.

The OPSCCs were more frequently basaloid $(\mathrm{p}<0.001)$ while the OSCCs were more frequently conventional $(\mathrm{p}<0.000001)$. The OSCCs were more likely to recur locally and to be the cause of death ( $\mathrm{p}=0.009$ in both parameters).

The HPV-positive tumors were more frequently localized in oropharynx, were basaloid SCCs and were p16- and HPV-positive ( $\mathrm{p}<0.000001$ in all 4 parameters). The HPV-negative tumors were more frequently localized in oral cavity $(\mathrm{p}<0.000001)$, more frequently asociated with local, regional and locoregional recurence $(\mathrm{p}=0.011, \mathrm{p}=0.019$ and $\mathrm{p}=0.030$, respectively) and with tumor-related death $(\mathrm{p}=0.003)$. There was no significant difference with regard to smoking history $(\mathrm{p}>0.05)$.

The survival of patients with HPV-positive tumors was significantly longer (median 112 months; $95 \%$ CI 54 - 112 months) than that of patients with HPV-negative tumors (median 17 months; 95\% CI 12 - 39 months) $(\mathrm{p}<0.001)$.

The HPV status of OSCC/OPSCC is an important biological and prognostic parameter and should be examined in all cases, using PCR or immunohistochemical detection of surrogate marker p16. Smoking itself does not seem to be an important prognostic factor.
\end{abstract}

Key words: squamous cell carcinoma, oral cavity, oropharynx, p16 protein, HPV, prognostic factors

Head and neck cancer is the sixth most common type of cancer, accounting for about $6 \%$ of all human malignancies [1]. The most common cancer type in this anatomic area is squamous cell carcinoma (SCC), traditionally associated with smoking and alcohol abuse. Since the 1990s, however, evidence has been emerging suggesting that a subset of oropharyngeal
SCCs (OPSCCs) is associated with oral high-risk human papillomavirus (HR-HPV) infection, which may precede the development of SCC by more than 20 years [2].

The prevalence of HPV-positive head and neck SCCs (HNSCCs) shows considerable regional variation, partly because of true geographic differences in the prevalence of oral 
HPV infection and partly because of different HPV detection methods used in various studies [3]. In the last two decades, at least 40 studies on this topic were published in the English literature, reporting HPV-positive HNSCC prevalences from 0 to $93 \%$ [4]. In a multicenter case-control study organized by the International Agency for Research on Cancer published in 2007, a total of $70 \%$ of HNSCCs were shown to harbour HPV DNA, with HPV 16 being the most commonly observed type [5].

The incidence of HPV-positive HNSCCs is increasing worldwide. A recent study from Sweden reports that while in the 1970 s $23 \%$ of tonsillar carcinomas were HPV-positive, 93\% positivity was recorded in 2006-2007 [6]. Several authors even suggest an "epidemic" of HPV-positive HNSCCs [7, 8].

HPV-positive HNSCC seems to be a distinct clinicopathologic entity [9]. The tumors occur in younger patients - frequently in nonsmokers with multiple sex partners and oral-genital sexual practices. They are frequently localized in the oropharynx, show basaloid morphology on microscopy, display minimal p53 expression and rarely show chromosomal aberrations. Prognosis is favourable despite frequent regional lymph node metastases. The opposite is true for most of the HPV-negative HNSCCs $[8,9]$.

As a continuation of our previous study on the role of HPV in the etiopathogenesis of HNSCCs in nonsmokers [10], we included a group of smokers and also expanded the spectrum of evaluated clinicopathological parameters. The aim of the current study was to compare (i) nonsmokers to smokers, (ii) OSCCs to OPSCCs, and most importantly, (iii) HPV-positive to HPV-negative SCCs.

\section{Patients and methods}

An institutional database search revealed a total of 307 OSCCs and 228 OPSCCs diagnosed between 2000 and 2010 at The Fingerland Department of Pathology, Faculty Hospital, Hradec Kralove, Czech Republic in surgical resection specimens. Because of the important role of actinic damage in the etiopathogenesis of SCC of lip, these tumors were excluded from the search and study. Ethical approval was obtained prior to the study from the Ethics Committee, Faculty Hospital Hradec Kralove.

Twenty-four ( $8 \%$ ) of the 307 patients with OSCC and 22 ( $10 \%)$ of the 228 patients with OPSCC had no personal history of either smoking or chronic alcohol abuse. These patients comprised the nonsmoker group. A smoker group, comprising gender-and decade of age-matched patients who were further matched for tumor localization (oral cavity versus oropharynx) and the year of operation, was selected for comparison. None of the patients in either group had undergone neoadjuvant therapy. For every patient, gender and age were recorded.

Tumors occurring in the oral vestibulum, on the cheek, hard palate, floor of mouth, gingival/alveolar mucosa, and on the anterior tongue (the first $2 / 3$ of tongue) were classified as OSCCs, whereas the group OPSCCs included tumors of the root of tongue, palatine tonsils and arches, soft palate, and the posterior wall of oropharynx [11]. In every case, tumor size ("pT"), presence of regional lymph node metastases (" $\mathrm{pN}^{\prime \prime)}$ ) and presence of distant metastases were recorded. Where pathologic lymph node and metastasis status were unavailable, clinical data ("cN" and "cM") was used. Histologic subtypes of SCC ("conventional", verrucous, basaloid, papillary, spindle cell, acantholytic, adenosquamous, and carcinoma cuniculatum) and differentiation grade of "conventional" SCC were recorded according to the current WHO classification of head and neck tumors [11]. Pathologic staging was established from tumor resection/excision and neck lymph node dissection specimens according to current TNM classification [12].

After resection, the specimens were immediately fixed in $10 \%$ formalin, routinely processed, embedded in paraffin and stained with hematoxylin-eosin. Paraffin blocks for further analysis were available in all cases.

For immunohistochemical detection of $\mathrm{p} 16^{\mathrm{INK} 4 \mathrm{a}}$ protein (p16), the CINtec ${ }^{\oplus}$ Histology Kit (mtm laboratories AG, Heidelberg, Germany) was used according to the manufacturer's manual. Samples of cervical intraepithelial lesion grade III were used as positive controls. Control slides provided by the manufacturer were used as negative controls. Brown staining of tumor cell nuclei and/or cytoplasm was interpreted as positive. The p16 immunostaining was scored according to criteria set out in our previous studies $[10,13]$ as follows: (0) absent, (+) 1-5\% tumor cells stained, (++) 6-20\% tumor cells stained, (+++) 21-50\% tumor cells stained, and (++++) 51-100\% tumor cells stained.

The HPV DNA detection was performed by polymerase chain reaction (PCR) as follows. The HPV DNA was extracted from paraffin-embedded tissue after deparaffinization in xylen and rehydration in ethanol using the commercial QIAamp DNA FFPE Tissue Kit (Qiagen GmBH, Hilden, Germany) according to the manufacturer's protocol. PCR amplification of $\beta$-globin sequences was performed to confirm sample fitness for PCR assay. All samples were screened for presence of HPV DNA by PCR amplification with primers GP5+/GP6+ located within the HPV L1 gene. The sequences of the forward and reverse primers used were $5^{\prime}$-TTTGTTACTGTGGTAGATACTAC3' (GP5+) and 5'-GAAAAATAAACTGTAAATCATATT-3' (GP6+). The PCR reaction was performed in a volume of 25 $\mu \mathrm{L}$, containing $25 \mathrm{mM} \mathrm{MgCl}_{2}, 2.5 \mathrm{mM}$ of each dNTP, 2.5 units of Takara Taq polymerase (Takara Bio Inc., Shiga, Japan), 100 pmol of each primer (GP5+/GP6+) and $2 \mu \mathrm{L}$ of HPV DNA at various dilutions. The PCR protocol was then carried out with an initial denaturation at $95^{\circ} \mathrm{C}$ for $10 \mathrm{~min}$, followed by 40 cycles of denaturation at $95^{\circ} \mathrm{C}$ for $30 \mathrm{~s}$, annealing at $55^{\circ} \mathrm{C}$ for $60 \mathrm{~s}$, and extension at $72^{\circ} \mathrm{C}$ for $45 \mathrm{~s}$. Amplified products were run on $2 \%$ agarose gel and stained with ethidium bromide for size verification.

Samples showing HPV DNA presence by the above mentioned procedure were subsequently analyzed using Linear Array HPV Genotyping Test (Roche, Basel, Switzerland). The 
manufacturer's protocol was modified to adapt the test for use on paraffin-embedded tissue according to Siriaunkgul et al. [14]. The test involves three steps: PCR amplification of target DNA, nucleic acid hybridization, and detection of $37 \mathrm{HPV}$ types, specifically $6,11,16,18,26,31,33,35,39,40,42,45,51$, $52,53,54,55,56,58,59,61,62,64,66,67,68,69,70,71,72,73$ (MM9), 81, 82 (MM4), 83 (MM7), 84 (MM8), IS39 a CP6108. PCR was performed in a total volume of $100 \mu \mathrm{L}$ containing 50 $\mu \mathrm{L}$ of the manufacturer's master mix and $50 \mu \mathrm{L}$ of GP5+/GP6+ PCR product. The amplification program consisted of $2 \mathrm{~min}$ at $50^{\circ} \mathrm{C}$, and $9 \mathrm{~min}$ at $95^{\circ} \mathrm{C}$, followed by 40 cycles of $30 \mathrm{~s}$ at $50^{\circ} \mathrm{C}$, of $1 \mathrm{~min}$ at $55^{\circ} \mathrm{C}$, and of $1 \mathrm{~min}$ at $72^{\circ} \mathrm{C}$, with a final extension at $72^{\circ} \mathrm{C}$ for $5 \mathrm{~min}$. The PCR product was denaturated with denaturation solution and hybridized on to a strip containing specific probes for the 37 above mentioned HPV types and $\beta$-globin reference lines. Detection was carried out using streptavidin-HRP and $0.1 \%$ tetramethylbenzidine as a chromogen. Positive reaction was visible as a blue line on the strip.

The study was terminated on May 31, 2011. During the follow-up period, type of adjuvant therapy and data on local and regional recurrence, occurrence of distant metastases, development of other metachronous malignant tumors (except of squamous cell and basal cell carcinoma of skin), and tumor-associated death were recorded.

Statistical analysis using NCSS 2007 program, chi-squared test, Fisher's exact test, two-sample t-test, Mann-Whitney test, Kolmogorov-Smirnov test, Kaplan-Meier curve, log-rank tests and Cox regression analysis was performed. Differences were considered statistically significant at $\mathrm{p}<0.05$.

\section{Results}

\section{Descriptive characteristics}

Nonsmoker group. The nonsmoker group comprised 24 patients with OSCC and 22 patients with OPSCC. There were
23 males and 23 females, aged 35 - 93 years (mean $63 \pm 15$ years; median 61 years); the males were aged $35-86$ years (mean $60 \pm 11$ years; median 60 years), and the females $43-93$ years (mean $63 \pm 14$ years; median 64 years). Of the OSCCs, 8 were located on the anterior tongue, 6 on cheek, 5 on the gingiva/alveolar mucosa, 3 on floor of mouth, and 2 on the hard palate. The OPSCCs comprised 17 SCCs of the palatine tonsils, and 5 SCCs of the root of the tongue.

In 44/46 (96\%) patients follow-up data and information on adjuvant therapy were available. The follow-up period ranged from 18 - 168 months (mean $62 \pm 40$ months; median 53 months); for OSCC patients it ranged 18 - 110 months (mean $41 \pm 24$ months; median 28 months), and for OPSCC patients 19 - 168 months (mean $83 \pm 43$ months; median 79 months). The treatment modalities are detailed in Table 1. During the follow-up period, 12/44 (27\%) patients experienced local recurrence, 11/44 (25\%) regional recurrence, 17/44 (39\%) locoregional recurrence, $3 / 44(7 \%)$ distant metastases ( $2 \mathrm{x}$ skeleton, $1 \mathrm{x}$ liver), and 23/44 (52\%) patients died of carcinoma. Eight of $44(18 \%)$ patients developed a second malignant tumor (1x SCC of anterior tongue, 1x SCC of larynx, 1x SCC of lung, 1x adenocarcinoma of lung, $1 \mathrm{x}$ colonic adenocarcinoma, $1 \mathrm{x}$ chronic lymphocytic leukemia/small lymphocytic lymphoma, $1 \mathrm{x}$ diffuse large B-cell lymphoma and 1x Langerhans cell histiocytosis). The course of the disease is shown in Table 2.

The TNM status is detailed in Table 3. Most of the OSCCs were diagnosed in the advanced "pT4a" stage (in 8/24 (33\%) patients), whereas OPSCCs most commonly presented in the "pT2" status (in 12/22 (55\%) patients). The "pN" status was available in $32 / 46(70 \%)$ cases; in 15/24 (63\%) of the OSCCs and in $17 / 22(77 \%)$ of the OPSCCs. The number of lymph nodes examined ranged $3-33$ (mean $10 \pm 5$ nodes; median 10 nodes). Lymph node metastases, documented either clinically or microscopically, were present in $29 / 46$ (63\%) cases; in 11/24 ( $46 \%$ ) of the OSCCs and in 18/22 (82\%) of the OPSCCs. All but one of the tumors with "N2" fell into the "N2b" category.

Table 1. Treatment modalities in the patients groups

\begin{tabular}{|c|c|c|c|c|c|}
\hline & \multicolumn{3}{|c|}{ Radical resection } & \multicolumn{2}{|c|}{ Radiotherapy } \\
\hline & No adjuvant therapy & Adjuvant radiotherapy & Adjuvant chemoradiotherapy & Without chemotherapy & With chemotherapy \\
\hline \multicolumn{6}{|c|}{ Nonsmoker group } \\
\hline $\begin{array}{l}\text { OSCC }^{*} \\
(n=24)\end{array}$ & 2 & 9 & 6 & 4 & 1 \\
\hline $\begin{array}{l}\text { OPSCC } \\
(n=22)\end{array}$ & 1 & 11 & 10 & 0 & 0 \\
\hline \multicolumn{6}{|c|}{ Smoker group } \\
\hline $\begin{array}{l}\mathrm{OSCC}^{*} \\
(\mathrm{n}=24)\end{array}$ & 9 & 9 & 2 & 0 & 2 \\
\hline $\begin{array}{l}\text { OPSCC }^{\star *} \\
(\mathrm{n}=22)\end{array}$ & 1 & 15 & 5 & 0 & 0 \\
\hline $\begin{array}{l}\text { Total } \\
(n=92)\end{array}$ & 13 & 44 & 23 & 4 & 3 \\
\hline
\end{tabular}

OSCC $=$ oral squamous cell carcinoma; OPSCC $=$ oropharyngeal squamous cell carcinoma

Note: ${ }^{*}$ information available in 22 patients; ${ }^{* *}$ information available in 21 patients 
The exceptional case was a " $\mathrm{CN} 2 \mathrm{c}$ ". None of the patients presented with distant metastases ("cM0" status).

Smoker group. The smoker group comprised 24 patients with OSCC and 22 patients with OPSCC. There were 23 males and 23 females, aged $41-72$ years (mean $58 \pm 7$ years; median 57 years). Males were aged $47-70$ years (mean $58 \pm 7$ years; median 57 years) and females $41-72$ years (mean $57 \pm 8$ years; median 58 years).

In 43/46 (94\%) cases follow-up data and information on adjuvant therapy were available. The follow-up period ranged from 13 - 119 months (mean $47 \pm 29$ months; median 40 months); for OSCC patients: 13 - 106 months (mean $38 \pm$ 28 months; median 36 months), and for OPSCC patients: 15 - 119 months (mean $57 \pm 26$ months; median 60 months). The treatment modalities are detailed in Table 1. During the follow-up period, 10/43 (23\%) patients experienced local recurrence, $8 / 43$ (19\%) regional recurrence, 13/43 (30\%) locoregional recurrence, 5/43 (12\%) distant metastases (4x lung, 1x thoracic wall), and 23/43 (54\%) patients died of carcinoma. Four of 43 (9\%) patients subsequently developed a second malignant tumor (1x SCC of lung, 1x colonic adenocarcinoma, $1 \mathrm{x}$ urothelial carcinoma of urinary bladder, $1 \mathrm{x}$ malignant fibrous histiocytoma of soft tissues). The course of the disease is shown in Table 2.

The TNM status is detailed in Table 3. A majority of the OSCCs were diagnosed in the "pT2" (in 10/24 (43\%) patients) and in the advanced "pT4a" stages (in 9/24 (38\%) patients). OPSCCs most commonly presented in the "pT2" status (in $18 / 22$ (82\%) patients). The "pN" status was available in 40/46 (87\%) cases; in 20/24 (83\%) of the OSCCs and in 20/22 (91\%) of the OPSCCs. The number of lymph nodes examined ranged 4 - 36 (mean $11 \pm 6$ nodes; median 10 nodes). Considering the " $\mathrm{pN}$ " and the " $\mathrm{cN}$ " status together, metastases were present in $28 / 46$ (61 \%) cases; in 12/24 (50\%) of the OSCCs and in $16 / 22$

Table 2. Clinical course of the disease in the patients groups

\begin{tabular}{|c|c|c|c|c|c|c|}
\hline & Local recurrence & Regional recurrence & Locoregional recurrence & Distant metastases & Tumor-related death & Second malignancy \\
\hline \multicolumn{7}{|c|}{ Nonsmoker group } \\
\hline $\begin{array}{l}\text { OSCC }^{*} \\
(\mathrm{n}=24)\end{array}$ & 9 & 10 & 12 & 1 & 16 & 5 \\
\hline $\begin{array}{l}\text { OPSCC } \\
(\mathrm{n}=22)\end{array}$ & 3 & 1 & 5 & 2 & 7 & 3 \\
\hline \multicolumn{7}{|c|}{ Smoker group } \\
\hline $\begin{array}{l}\text { OSCC }^{*} \\
(\mathrm{n}=24)\end{array}$ & 9 & 4 & 9 & 4 & 16 & 1 \\
\hline $\begin{array}{l}\text { OPSCC }^{* *} \\
(\mathrm{n}=22)\end{array}$ & 1 & 4 & 4 & 1 & 7 & 3 \\
\hline $\begin{array}{l}\text { Total } \\
(\mathrm{n}=92)\end{array}$ & 22 & 19 & 30 & 8 & 46 & 12 \\
\hline
\end{tabular}

OSCC $=$ oral squamous cell carcinoma; OPSCC $=$ oropharyngeal squamous cell carcinoma

Note: ${ }^{*}$ information available in 22 patients; ${ }^{* *}$ information available in 21 patients

Note: Several patients developed more than 1 complication.

Table 3. TNM staging of the disease in the patients groups

\begin{tabular}{|c|c|c|c|c|c|c|c|c|}
\hline & \multicolumn{4}{|c|}{ pT } & \multicolumn{4}{|c|}{$\mathrm{N}$} \\
\hline & $\mathrm{T} 1$ & $\mathrm{~T} 2$ & $\mathrm{~T} 3$ & $\mathrm{~T} 4$ & $\begin{array}{l}\text { pN0 } \\
+\mathrm{cN} 0 \\
\end{array}$ & $\begin{array}{c}\mathrm{pN} 1 \\
+\mathrm{cN} 1 \\
\end{array}$ & $\begin{array}{c}\mathrm{pN} 2 \\
+\mathrm{cN} 2 \\
\end{array}$ & $\begin{array}{c}\mathrm{pN} 3 \\
+\mathrm{cN} 3 \\
\end{array}$ \\
\hline \multicolumn{9}{|c|}{ Nonsmoker group } \\
\hline $\begin{array}{l}\text { OSCC } \\
(\mathrm{n}=24)\end{array}$ & 6 & 6 & 4 & 8 & $4+9$ & $4+0$ & $7+0$ & $0+0$ \\
\hline $\begin{array}{l}\text { OPSCC } \\
(\mathrm{n}=22)\end{array}$ & 1 & 12 & 5 & 4 & $2+2$ & $4+0$ & $9+2$ & $2+1$ \\
\hline \multicolumn{9}{|c|}{ Smoker group } \\
\hline $\begin{array}{l}\text { OSCC } \\
(\mathrm{n}=24)\end{array}$ & 4 & 10 & 1 & 9 & $10+2$ & $3+0$ & $7+2$ & $0+0$ \\
\hline $\begin{array}{l}\text { OPSCC } \\
(\mathrm{n}=22)\end{array}$ & 3 & 18 & 1 & 0 & $5+1$ & $1+0$ & $13+2$ & $0+0$ \\
\hline $\begin{array}{l}\text { Total } \\
(\mathrm{n}=92)\end{array}$ & 14 & 46 & 11 & 21 & $21+14$ & $12+0$ & $36+6$ & $2+1$ \\
\hline
\end{tabular}

OSCC $=$ oral squamous cell carcinoma; OPSCC $=$ oropharyngeal squamous cell carcinoma 


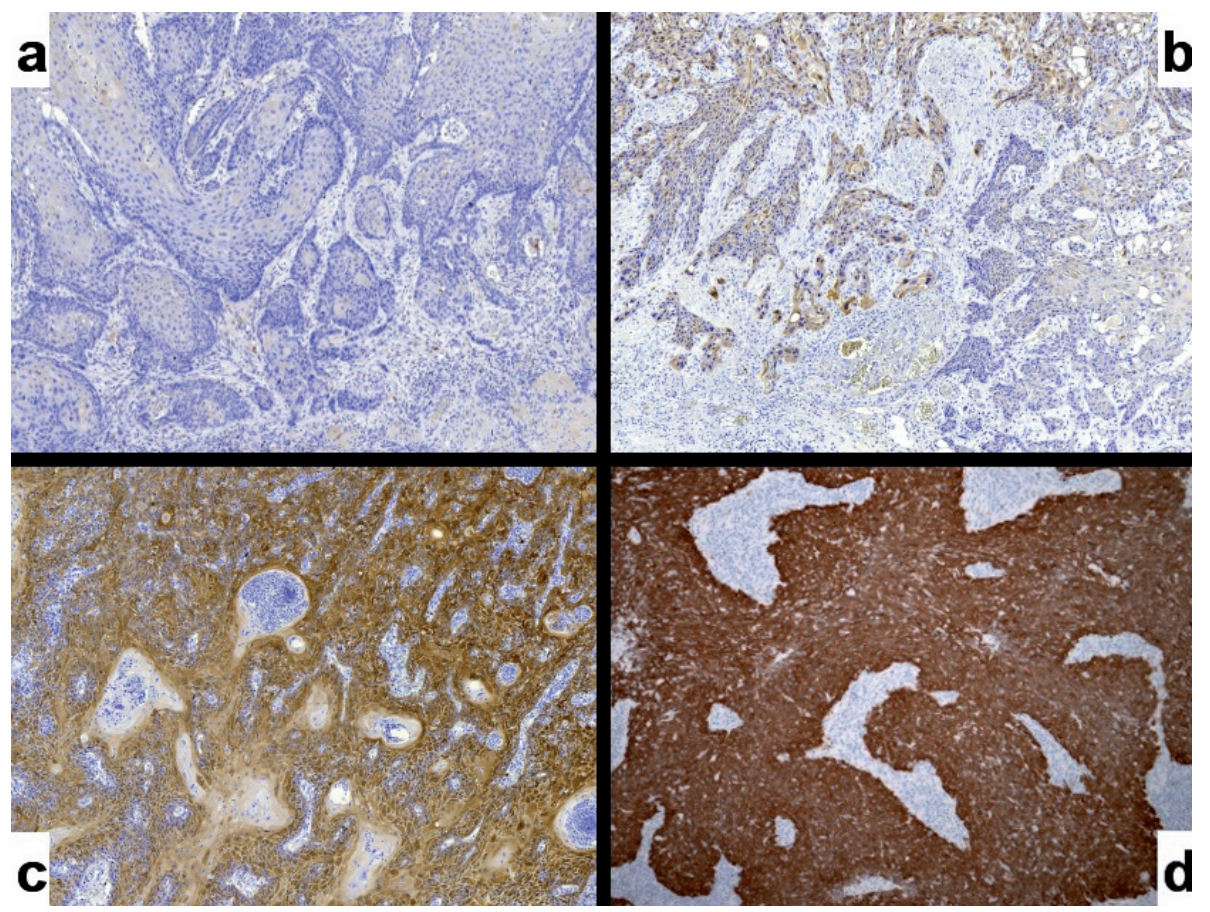

Figure 1. Figures (a-d) depict various patterns of p16 expression, with comments on HPV status, assessed by polymerase chain reaction. a) Mild, barely visible p16 expression in isolated tumor cells (upper left) in conventional OSCC; HPV DNA absent. b) Focal moderate expression of p16 in conventional OSCC; HPV DNA absent. c) Diffuse strong expression of p16 in deeper portion of conventional OSCC; HPV 16 DNA present. d) Diffuse strong expression of p16 in basaloid OPSCC; HPV 16 DNA present. (all figures, original magnification 100x).

(73\%) of the OPSCCs, with the "N2" status being the most common and, except for 4 cases of "pN2a" and 1 case of "cN2c", it corresponded to "N2b". None of the patients presented with distant metastases ("cM0" status).

\section{Microscopic, immunohistochemical and molecular findings}

Nonsmoker group. The microscopic findings are listed in Table 4 . All but one of the OSSCs were classified as conventional SCCs: grade 1 in 5/23 (22\%) cases, grade 2 in 17/23 (74\%) cases and grade 3 in 1/23 (4\%) case. This remaining case was a sarcomatoid variant. Twenty of the 22 (90\%) OPSCCs were classified as basaloid. Only 2 of the OPSCCs were conventional SCCs (grade 2) and both were located in the palatine tonsils. The morphological appearance of the lymph node metastases was the same as seen in the primary tumor. Transcapsular spread of metastasizing tumor cells was found in one case, a SCC of the cheek.

The results of p16 expression are shown in Table 5. The p16 expression was detected in 9/24 (38\%) OSCCs. All 22/22 (100\%) OPSCCs showed strong p16 expression in more than $90 \%$ of tumor cells (Fig. 1).

Table 4. Microscopic findings in the primary tumors in the patients groups

\begin{tabular}{|c|c|c|c|c|c|}
\hline & \multicolumn{2}{|c|}{ SCC variant } & \multirow{2}{*}{ Angioinvasion } & \multirow{2}{*}{ Perineural spread } & \multirow{2}{*}{$\begin{array}{l}\text { Positive resection } \\
\text { margin }\end{array}$} \\
\hline & conventional & basaloid & & & \\
\hline \multicolumn{6}{|c|}{ Nonsmoker group } \\
\hline $\operatorname{OSCC}^{\star}(\mathrm{n}=24)$ & 23 & 0 & 13 & 7 & 16 \\
\hline $\operatorname{OPSCC}(\mathrm{n}=22)$ & 1 & 21 & 19 & 5 & 12 \\
\hline \multicolumn{6}{|c|}{ Smoker group } \\
\hline OSCC $(n=24)$ & 24 & 0 & 13 & 8 & 15 \\
\hline $\operatorname{OPSCC}(n=22)$ & 12 & 10 & 16 & 1 & 7 \\
\hline Total $^{*}(\mathrm{n}=91)$ & 60 & 31 & 61 & 21 & 50 \\
\hline
\end{tabular}

OSCC $=$ oral squamous cell carcinoma; OPSCC $=$ oropharyngeal squamous cell carcinoma

${ }^{\star} 1$ sarcomatoid SCC is not listed 
Among the OSCCs, HPV DNA was found in 2/24 (8\%) cases; in a SCC of the alveolar mucosa and a SCC of the anterior tongue. In both cases the detected type was HPV 16. Among the OPSCCs, HPV DNA was found in 19/22 (86\%) cases. The detected type was HPV 16 in 17 cases and HPV 33 in 2 cases.

Smoker group. The microscopic findings are listed in Table 4. All OSCCs (24/24 (100\%)) were classified as conventional; grade 1 in $1 / 24(4 \%)$ case, grade 2 in $22 / 24(92 \%)$ cases and grade 3 in 1/24 (4\%) case. Twelve of the 22 (55\%) OPSCCs were classified as conventional and 10/22 (45\%) as basaloid. The morphological appearance of the lymph node metastases matched that of the primary tumors. Transcapsular spread of metastasizing tumor cells was found in 3 cases ( $1 x$ SCC of the floor of the mouth, 2x SCC of the palatinal tonsil).

The results of p16 expression are shown in Table 5. The p16 expression was detected in 8/24 (33\%) OSCCs and in 14 of the $22(64 \%)$ OPSCCs.

Among the OSCCs, HPV DNA was found in 5/24 (21\%) cases; 4 SCCs of the floor of the mouth and 1 SCC of the alveolar mucosa. In 4 cases the detected type was HPV 16 and in the 5th case, typization failed. Among the OPSCCs, HPV DNA was found in 16/22 (73\%) cases; HPV 16 in 14 cases, HPV 35 in one case and in the remaining case typization failed.

Comparison of HPV detection methods. Regarding the entire study sample (92 patients), there were 17/48 (35\%) p16-positive OSCCs and 36/44 (82\%) p16-positive OPSCCs. HPV DNA was detected in 7/48 (15\%) OSCCs and in 35/44 (80\%) OPSCCs, with HPV 16 being present in 36/39 (92\%) cases, HPV 33 in 2/39 (5\%) cases and HPV 35 in 1/39 (3\%) case. Neither presence of low-risk HPV DNA nor coinfection was observed in any of the tumors analyzed. On the optimal threshold of $20 \%$ p16-positive tumor cells, the sensitivity, specificity, positive predictive value and negative predictive value of p16 expression for HPV DNA presence were 0.74, $0.88,0.84$ and 0.80 , respectively. At the same threshold level, the $\phi$ and $\kappa$ index of p16 expression for HPV DNA presence were 0.628 and 0.624 , respectively, indicating moderate degree of correlation.

Statistical analysis. The following groups were compared (i) nonsmokers versus smokers, (ii) OSCCs versus OPSCCs, and (iii) HPV-positive versus HPV-negative SCCs.

When comparing nonsmokers to smokers, only the following parameters were significant: a) in nonsmokers, the basaloid variant of SCC was more common $(p=0.026)$, and b) the conventional variant of SCC was more frequently well differentiated $(\mathrm{p}=0.035)$.

When comparing OSCCs to OPSCCs, the OPSCCs were more frequently basaloid $(\mathrm{p}<0.001)$ or poorly differentiated conventional SCCs $(p=0.015)$, resected with negative margins $(\mathrm{p}=0.037)$, $\mathrm{p} 16$-positive $(\mathrm{p}<0.001)$ and HPV-positive $(\mathrm{p}<0.001)$. On the contrary, OSCCs were more frequently conventional $(\mathrm{p}<0.000001)$, without angioinvasion $(\mathrm{p}=$ $0.026)$ or lymph node metastasis $(\mathrm{p}=0.046)$, with perineural spread $(\mathrm{p}=0.023)$, and the patient did not receive adjuvant

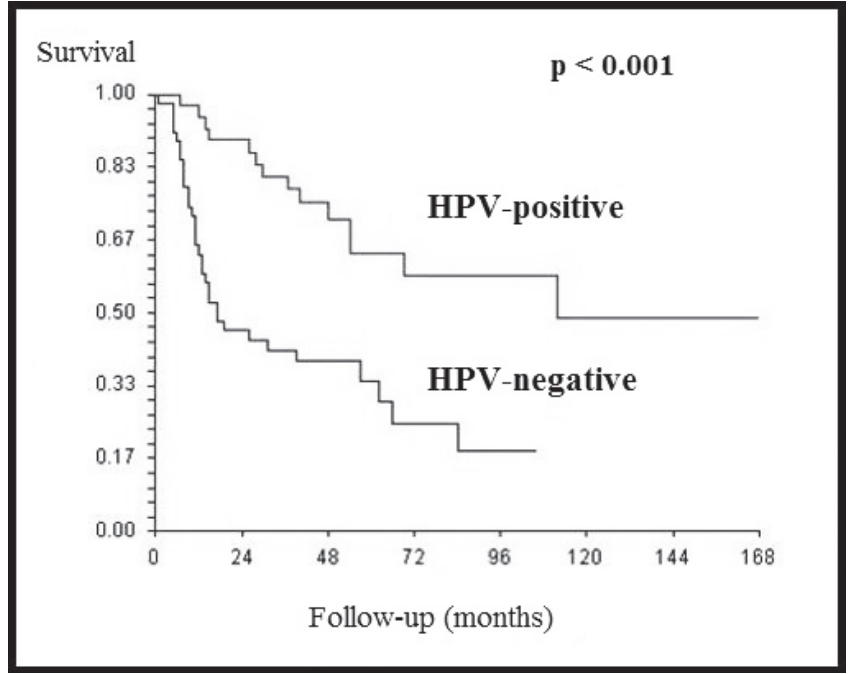

Figure 2. Comparison of survival between patients with HPV-positive and HPV-negative tumor

radiotherapy $(p=0.001)$. In addition, OSCCs more frequently recurred locally $(\mathrm{p}=0.009)$, regionally $(\mathrm{p}=0.004)$ and locoregionally $(\mathrm{p}=0.030)$, and there were more tumor-related deaths $(\mathrm{p}=0.009)$.

The results of comparison between HPV-positive and HPV-negative SCCs are shown in Table 6. Most importantly, the HPV-positive tumors were more frequently localized in the oropharynx $(\mathrm{p}<0.000001)$. They were frequently basaloid $(\mathrm{p}<0.000001)$ or poorly differentiated conventional SCCs $(\mathrm{p}=0.008)$. The tumors typically showed $\mathrm{p} 16$-positivity $(\mathrm{p}<$ $0.000001)$. On the contrary, the HPV-negative tumors were more frequently localized in oral cavity $(\mathrm{p}<0.000001)$. Local

Table 5. Results of p16 expression and HPV DNA presence in the patients groups

\begin{tabular}{lccccccc}
\hline & \multicolumn{5}{c}{ p16 protein expression } & \multicolumn{3}{c}{ HPV DNA PCR } \\
\cline { 2 - 7 } & 0 & + & ++ & +++ & ++++ & negative & positive \\
\hline \multicolumn{7}{c}{ Nonsmoker group } \\
\hline $\begin{array}{l}\text { OSCC } \\
(\mathrm{n}=24)\end{array}$ & 15 & 6 & 2 & 1 & 0 & 22 & 2 \\
$\begin{array}{l}\text { OPSCC } \\
(\mathrm{n}=22)\end{array}$ & 0 & 0 & 0 & 0 & 22 & 3 & 19 \\
\hline \multicolumn{7}{c}{ Smoker group } \\
\hline $\begin{array}{l}\text { OSCC } \\
(\mathrm{n}=24)\end{array}$ & 16 & 5 & 2 & 1 & 0 & 19 & 5 \\
$\begin{array}{l}\text { OPSCC } \\
(\mathrm{n}=22)\end{array}$ & 8 & 1 & 0 & 0 & 13 & 6 & 16 \\
\hline $\begin{array}{l}\text { Total } \\
(\mathrm{n}=92)\end{array}$ & 39 & 12 & 4 & 2 & 35 & 50 & 42 \\
\hline
\end{tabular}

HPV = human papillomaviruses; OSCC $=$ oral squamous cell carcinoma; OPSCC $=$ oropharyngeal squamous cell carcinoma; PCR = polymerase chain reaction 
and regional and locoregional recurrences were frequent $(\mathrm{p}=$ $0.011, p=0.019$, and $p=0.300$, respectively), and there were more tumor-related deaths $(p=0.003)$. Interestingly, there was no statistically significant difference with regard to smoking history $(\mathrm{p}>0.05)$.

Survival analysis was performed with awareness of possible limitations of the results due to the therapeutical heterogeneity of our study sample.

In the nonsmoker group, the survival ranged between 6 and 168 months (median 62 months; 95\% confidence interval (CI) $39-112$ months), whereas in the smoker group it ranged 1 - 119 months (median 48 months; 95\% CI 19 - 66 months). No statistically significant difference was found.

In the nonsmoker group, the survival of patients with OSCC ranged 6 - 98 months (median 15 months; 95\% CI 10 - 39 months), whereas in patients with OPSCC it ranged 7 168 months (95\% CI $84-112$ months). In the smoker group, the survival of patients with OSCC ranged $1-106$ months (median 14 months; 95\% CI 11 - 19 months), whereas of patients with OPSCC it ranged $3-119$ months (median 66 months; 95\% CI 44 - 66 months). In both nonsmoker and smoker groups, there was statistically significant difference in survival between patients with OSCC and OPSCC ( $p<$ $0.001 ; \mathrm{p}=0.020$ ).

Regarding the whole study sample (92 patients), the survival of patients with HPV-positive tumors ranged $3-168$ months (median 112 months; 95\% CI 54 - 112 months), whereas of patients with HPV-negative tumors it ranged $1-106$ months (median 17 months; 95\% CI 12 - 39 months). The difference is statistically significant $(\mathrm{p}<0.001)$ (Fig 2).

Using the Cox regression analysis, the most significant parameters influencing survival were tumor localization ( $\mathrm{p}$ $=0.002)$, " $\mathrm{N}$ " status $(\mathrm{p}=0.038)$, status of resection margins $(\mathrm{p}=0.040)$, HPV status $(\mathrm{p}=0.045)$, and $\mathrm{p} 16$ expression $(\mathrm{p}=$ 0.048 ). Specifically, the characteristics favouring longer survival are localization of the tumor in oropharynx, "N0" status, negative resection margins, presence of HPV DNA, and p16 expression. The coefficient of determination of the model was $\mathrm{R}^{2}=0.308$, indicating its relevance only for description, not for prediction. However, in general the model is statistically significant $(\mathrm{p}<0.0001)$.

\section{Discussion}

Nowadays, HPVs are recognized as important human pathogens. Given their oncogenic potential, mucosal HPVs, which show affinity for the anogenital area and upper aerodigestive tract, are classified into low-risk and high-risk (HR-HPV) types. While the former cause benign lesions, e.g. squamous cell papillomas and condylomata, the latter are the major cause of cervical carcinoma and are associated with a subset of vulvar, vaginal, penile and anal cancers $[15,16]$. Since the first suggestion on the role of HPV in the etiopathogenesis of HNSCCs by Syriänen et al. in 1983 [17], at least 40 studies have been published on this topic providing good evidence that HPVs are associated with a subset of these tumors, particularly those occurring in the oropharynx $[4,18]$.

The precise proportion of HPV-positive HNSCCs, however, varies considerably, ranging from $0 \%$ up to $93 \%$ [4]. This discordance may be partially explained by true regional differences in the prevalence of oral HPV infection, probably influenced by differences of sexual habits in particular cultures, by precise anatomic localization of the tumors (oral cavity versus oropharynx) and by different HPV detection methods used in the studies [3]. In a multicentre case-control study on HNSCCs, $70 \%$ of tumors harboured HPV DNA [5]. Selected recent papers dealing with HPV in HNSCC are listed in Table $7[6,10,18-40]$. The HPV types detected in HNSCCs include most frequently HPVs 16, 18 and 33 [4, 9, 41]. Like in our study, the most common type was HPV 16, observed in $92 \%$ cases.

HPV-positive HNSCCs seem to constitute a distinct clinicopathological entity, different from HPV-negative tumors [9]. They tend to occur in youger patients (30-50s) without gender predilection. In addition, these cancers frequently develop in patients without traditional risk factors, i.e. smoking and alcohol abuse. Their risk factors include young age at first intercourse, promiscuity and history of genital warts [42].

Table 6. Comparison of HPV-positive versus HPV-negative SCCs

\begin{tabular}{lccc}
\hline Parameter & $\mathrm{p}$ & Parameter & $\mathrm{p}$ \\
\hline Smoking & $\mathrm{p}>0.05$ & "N"status & $\mathrm{p}>0.05$ \\
Gender & $\mathrm{p}>0.05$ & Adjuvant therapy & $\mathbf{p}<\mathbf{0 . 0 0 1}$ \\
Age & $\mathrm{p}>0.05$ & Local recurrence & $\mathbf{p}=\mathbf{0 . 0 1 1}$ \\
Localization & $\mathbf{p}<\mathbf{0 . 0 0 0 0 0 1}$ & Regional recurrence & $\mathbf{p}=\mathbf{0 . 0 1 9}$ \\
Variant of SCC & $\mathbf{p}<\mathbf{0 . 0 0 0 0 0 1}$ & Locoregional recurrence & $\mathbf{p}=\mathbf{0 . 0 3 0}$ \\
Differentiation grade of conventional SCC & $\mathbf{p}=\mathbf{0 . 0 0 8}$ & Distant metastases & $\mathrm{p}>0.05$ \\
Angioinvasion & $\mathrm{p}>0.05$ & Second malignancy & $\mathrm{p}>0.05$ \\
Perineural spread & $\mathrm{p}>0.05$ & Tumor-related death & $\mathbf{p}=\mathbf{0 . 0 0 3}$ \\
Status of resection margins & $\mathbf{p}=\mathbf{0 . 0 1 4}$ & $\mathrm{p} 16$ expression & $\mathbf{p}<\mathbf{0 . 0 0 0 0 0 1}$ \\
„pT“ status & $\mathbf{p}=\mathbf{0 . 0 3 2}$ & & \\
\hline
\end{tabular}

SCC $=$ squamous cell carcinoma 
Positive personal history of oral-genital and oral-anal sexual contact during which the HPV infection may be transmitted to the oral cavity increases the risk for HPV-positive HNSCCs, these tumors may be regarded as a sexually transmitted disease [4]. It is assumed that long lasting oral HR-HPV infection precedes development of HPV-positive HNSCC about 20 years $[5,7]$. Thus, some authors consider the present epidemic of HPV-positive HNSCCs to be a consequence of the "sexual revolution" started in the western civilization circle in the 1960s [6, 8].

The influence of smoking on HPV-positive HNSCCs is yet unclear but both synergistic and additional effects have been suggested [4]. Although it is commonly stated that HPVpositive HNSCCs frequently develop in non-smoking patients, detailed data on this population are sparse. In our previous study [10], we showed that the vast majority of OPSCCs developing in nonsmokers are related to oral HR-HPV infection whereas, viral etiology is responsible for only a small subset of OSCCs, stressing the need for identification of further risk factors playing role in pathogenesis of the OSCC. In the current study, there was no statistically significant difference regarding all studied parameters (except for tumor morphology) between the nonsmoker and the smoker groups. This indicates, that smoking itself, although it is an important risk factor, seems not to be a prognostic factor.

$\mathrm{HPV}$-positive HNSCCs are prone to occur in the oropharynx, particularly in the palatine tonsils and at the root of the tongue, both areas rich in lymphoid tissue $[1,2]$. This characteristics has been confirmed in our study, with $80 \%$ of OPSCCs versus $15 \%$ of OSCCs being HPV-positive. The affinity of HPV to the oropharyngeal mucosa may be explained by production of currently unspecified cytokines by lymphoid tissue and/or by deep invaginations of the tonsilar surface, the latter factor blocking simple mechanical clearing of the epithelium and making it more susceptible to HPV infection [3].

Nowadays, PCR assay and the FDA-approved Hybrid Capture 2 assay serve as most reliable standard detection methods for HPV testing [43]. In addition, the immunohistochemical detection of $\mathrm{p} 16$, which is regarded as a sensitive marker of active HR-HPV replication, is widely used as a surrogate marker, particularly in cervical pathology, where its sensitivity and specificity for HPV presence were shown to be as high as $0.70-1.00$ and $0.70-0.97$, respectively [44]. The sensitivity and specificity of p16 expression for HPV DNA

Table 7. Selected recent studies on HPV in OSCC and OPSCC (2001-2011)

\begin{tabular}{|c|c|c|c|c|}
\hline Author & Tumor localization & Method & $\begin{array}{l}\text { HPV-positive } \\
\text { /Total (\%) }\end{array}$ & HPV type \\
\hline van Houten (19) & OSCC + OPSCC & PCR & $20 / 84(24)$ & 16 \\
\hline Kojima (20) & OSCC & PCR & $35 / 53(66)$ & 38 \\
\hline Sugiyama (21) & OSCC & PCR & $30 / 86(35)$ & 16 \\
\hline Smith (22) & OSCC + OPSCC & RT-PCR & $38 / 193(20)$ & $16,18,33$ \\
\hline Koppikar (23) & OSCC & PCR & $6 / 102(6)$ & $6,8,16,18,38$ \\
\hline Tachezy (24) & OSCC + OPSCC & PCR & $35 / 68(52)$ & 16,33 \\
\hline Slebos (25) & OSCC + OPSCC & RT-PCR & $8 / 36(22)$ & 16 \\
\hline El-Mofty (26) & OSCC + OPSCC & PCR & $120 / 235(51)$ & 16 \\
\hline Weinberger (26) & OPSCC & RT-PCR & $48 / 79(61)$ & 16 \\
\hline Luo (27) & OSCC & PCR & $13 / 51(25)$ & $16,18,33,52$ \\
\hline Chuang (28) & OSCC + OPSCC & RT-PCR & $20 / 59(34)$ & 16 \\
\hline Klozar (29) & OSCC + OPSCC & PCR & $52 / 81(64)$ & $16,26,33$ \\
\hline Lohavanichbutr (30) & OSCC + OPSCC & PCR & $41 / 119(35)$ & $16,32,35,45,53$ \\
\hline Gudleviciene (31) & OSCC + OPSCC & PCR & $13 / 48(27)$ & 16 \\
\hline Nasman (6) & OPSCC & PCR & $43 / 46(93)$ & $16,33,35,59$ \\
\hline Weinberger (32) & OPSCC & PCR/IHC & $47 / 77(61)$ & 16 \\
\hline Shi (33) & OPSCC & PCR/ISH/IHC & $73 / 111(66)$ & 16 \\
\hline Straetmans (34) & OPSCC & ISH & $33 / 81(41)$ & 16 \\
\hline Tachezy (35) & OSCC + OPSCC & PCR & $53 / 86(62)$ & $16,26,33$ \\
\hline Attner (36) & OPSCC & PCR & $71 / 95(75)$ & $16,33,35,58$ \\
\hline Bennett (37) & OPSCC & PCR & $9 / 16(56)$ & 16 \\
\hline Hoffmann (38) & OPSCC & RT-PCR/IHC & $21 / 39(53)$ & 16 \\
\hline Glombitza (18) & OSCC + OPSCC & PCR & $19 / 52(37)$ & 16,33 \\
\hline Lewis (39) & OPSCC & PCR/ISH/IHC & $161 / 239(67)$ & 16,33 \\
\hline Laco (10) & OSCC + OPSCC & PCR/ISH/IHC & $21 / 46(46)$ & 16,33 \\
\hline Rotnáglová (40) & OPSCC & PCR/ISH/IHC & $71 / 109(65)$ & $16,18,26,33,52,58$ \\
\hline
\end{tabular}

$\overline{\mathrm{IHC}}=$ immunohistochemistry; ISH = in situ hybridization; OPSCC = oropharyngeal squamous cell carcinoma; OSCC = oral squamous cell carcinoma; PCR = polymerase chain reaction; RT-PCR = real-time PCR 
presence detected by PCR were in our study 0.74 and 0.88 , respectively, confirming the use of this marker as an acceptable tool in testing the HPV status of HNSCCs. As it is not yet clear, whether p16 expression, or HPV DNA presence is a more important predictive parameter, testing of both characteristics is recommended. Recently, the HPV testing in exfoliated tumor cells from oral washings has been shown to be a reliable tool for determination the HPV tumor status, with sensitivity and specificity of 0.83 and 0.88 , respectively [35]. The detection of anti-E6/E7 antibodies in patients'sera seems to be an other promising method for indirect checking of HPV status of the HNSCCs [40].

Most importantly, compared with the HPV-negative tumors, HPV-positive HNSCCs show better outcome and reduced risk of recurrence with enhanced radiochemosensitivity [2,9]. For example, in the studies by Lassen et al. [45] and Fischer et al. [46] the 5-year survival of HPV-positive HNSCCs compared with HPV-negative tumors was $57 \%$ versus $27 \%$, and $62 \%$ versus $26 \%$, respectively. This difference was observed also in our study, as the HPV-negative tumors more frequently recurred locally $(\mathrm{p}=0.011)$, regionally $(\mathrm{p}=$ $0.019)$ and locoregionally $(\mathrm{p}=0.030)$ and the patients more frequently died because of the tumor $(p=0.003)$. Moreover, the survival of patients with HPV-positive tumors was significantly longer (median 112 months; 95\% CI 54 - 112 months) compared to patients with HPV-negative tumors (median 17 months; 95\% CI 12 - 39 months) ( $<$ 0.001). In our study, not surprisingly, both the HPV status and p16 expression were shown to be significant parameters influencing survival. However, because of the therapeutical heterogeneity in our study sample, interpretation of these results must be cautious. Although our results are in accordance with those of other studies, we ourselves regard them as preliminary at best.

In summary, we have shown that HPV-positive HNSCC represents a distinct clinicopathological entity with relatively favourable outcome. Development of more effective therapeutical options for their treatment in the near future is mandatory. Nowadays, the consideration is reduction of the radiation dose and omission of chemotherapy in adjuvant treatment. Therefore, the p16/HPV testing in every case of HNSCC is of particular importance and should become common practice.

Acknowledgements: The authors thank Mrs. M. Zakova for her excellent technical support. Research Project was supported by a grant of the Ministry of Health of the Czech Republic No. 00179906. / The study was supported by Research project of the Ministry of Health of the Czech Republic No. 00179906.

\section{References}

[1] ARGIRIS A, KARAMOUZIS MV, RABEN D, FERRIS RL. Head and neck cancer. Lancet 2008; 371: 1695-1709. http: //dx.doi.org/10.1016/S0140-6736(08)60728-X

[2] MANNARINI L, KRATOCHVIL V, CALABRESE L, GOMES SILVA L, MORBINI P et al. Human papilloma virus (HPV) in head and neck region: review of literature. Acta Otorhinolaryngol Ital 2009; 29: 119-126.

[3] NOVAKOVA V, LACO J. Role of human papillomavirus in carcinogenesis of head and neck cancer. Klin Onkol 2008; 21: 141-148.

[4] LAJER CB, VON BUCHWALD C. The role of human papillomavirus in head and neck cancer. APMIS 2010; 118: 510-519. http: //dx.doi.org/10.1111/j.1600-0463.2010.02624.x

[5] D'SOUZA G. Case-control study of human papillomavirus and oropharyngeal cancer. N Engl J Med 2007; 356: $1125-1131$.

[6] NASMAN A, ATTNER P, HAMMARSTEDT L, DU J, ERIKSSON M et al. Incidence of human papillomavirus (HPV) positive tonsillar carcinoma in Stockholm, Sweden: an epidemic of viral-induced carcinoma? Int J Cancer 2009; 125: 362-366. http: //dx.doi.org/10.1002/ijc.24339

[7] MARUR S, D'SOUZA G, WESTRA WH, FORASTIERE AA. HPV-associated head and neck cancer: a virus-related cancer epidemic. Lancet Oncol 2010; 11, 781-789. http: //dx.doi. org/10.1016/S1470-2045(10)70017-6

[8] NGUYEN NP, CHI A, NGUYEN LM, LY BH, KARLSSON $\mathrm{U}$ et al. Human papillomavirus-associated oropharyngeal cancer: a new clinical entity. Q J Med 2010; 103: 229-236. http: //dx.doi.org/10.1093/qjmed/hcp176

[9] GILLISON ML. Human papillomavirus-associated head and neck cancer is a distinct epidemiologic, clinical, and molecular entity. Semin Oncol 2004; 31: 744-754. http: //dx.doi. org/10.1053/j.seminoncol.2004.09.011

[10] LACO J, VOSMIKOVA H, NOVAKOVA V, CELAKOVSKY P, DOLEZALOVA H et al. The Role of High Risk Human Papillomavirus Infection in Oral and Oropharyngeal Squamous Cell Carcinoma in Non-smoking and Non-drinking Patients: a Clinicopathological and Molecular Study of 46 Cases. Virchow Arch 2011; 458: 179-187. http: //dx.doi. org/10.1007/s00428-010-1037-y

[11] SLOOTWEG PJ, EVESON JW. Tumours of the oral cavity and oropharynx. In: Barnes L, Eveson JW, Reichart P, Sidransky D (eds). World Health Organization Classification of Tumours. Pathology and Genetics of Head and Neck Tumours. Lyon: IARC Press, 2005

[12] SOBIN LH, GOSPODAROWICZ MK, WITTEKIND C (eds). TNM Classification of Malignant Tumours, 7th edn. WileyBlackwell, 2009.

[13] LACO J, SLANINKA I, JIRASEK M, CELAKOVSKY P, VOSMIKOVA $\mathrm{H}$ et al. High risk human papillomavirus infection and p16INK4a protein expression in laryngeal lesions. Pathol Res Pract 2008; 204: 545-552. http: //dx.doi.org/10.1016/ j.prp.2008.03.001

[14] SIRIAUNKGUL S, SUWIWAT S, SETTAKORN J, KHUNAMORNPONG S, TUNGSINMUNKONG K et al. HPV genotyping in cervical cancer in Northern Thailand: adapting the linear array HPV assay for use on paraffin-embedded tissue. Gynecol Oncol 2008; 108: 555-560. http: //dx.doi. org/10.1016/j.ygyno.2007.11.016

[15] ZUR HAUSEN. Papillomavirus and cancer: from basic studies to clinical application. Nat Rev Cancer 2002; 2: 342-350. http: /dx.doi.org/10.1038/nrc798 
[16] ZUR HAUSEN Papillomaviruses in the causation of human cancers - a brief historical account. Virology 2009; 384: 260-265. http://dx.doi.org/10.1016/j.virol.2008.11.046

[17] SYRJANEN K, SYRJANEN S, LAMBERG M, PYRHONEN S, NUUTINEN J. Morphological and immunohistochemical evidence suggesting human papillomavirus (HPV) involvement in oral squamous cell carcinogenesis. Int J Oral Surg 1983; 12: 418-424. http: //dx.doi.org/10.1016/S0300-9785(83)80033Z

[18] GLOMBITZA F, GUNTINAS-LICHIUS O, PETERSEN I. HPV status in head and neck tumors. Pathol Res Pract 2010; 206: 229-234. http: //dx.doi.org/10.1016/j.prp.2009.11.007

[19] VAN HOUTEN VM, SNIJDERS PJ, VAN DEN BREKEL MW, KUMMER A, MEIJER CJ et al. Biological evidence that human papillomaviruses are etiologically involved in a subgroup of head and neck squamous cell carcinoma. Int J Cancer 2001; 93: 232-235. http: //dx.doi.org/10.1002/ ijc. 1313

[20] KOJIMA A, MAEDA H, SUGITA Y, TANAKA S, KAMEYAMA Y. Human papillomavirus type 38 infection in oral squamous cell carcinoma. Oral Oncology 2002; 38: 591-596. http: //dx.doi.org/10.1016/S1368-8375(01)00112-9

[21] SUGIYAMA M, BHAWAL UK, DOHMEN T, ONO S, MIYAUCHI M et al.: Detection of human papillomavirus-16 and HPV-18 DNA in normal, dysplastic, and malignant oral epithelium. Oral Surg Oral Med Oral Pathol Oral Radiol Endod 2003; 95: 594-600. http: //dx.doi.org/10.1067/moe.2003.36

[22] SMITH EM, RITCHIE JM, SUMMERSGILL KF, KLUSSMANN JP, LEE JH et al. Age, sexual behavior and human papillomavirus infection in oral cavity and oropharyngeal cancers. Int J Cancer 2004; 108: 766-772. http: //dx.doi. org/10.1002/ijc. 11633

[23] KOPPIKAR P, DE VILLIERS EM, MULHERKAR R. Identification of human papillomaviruses in tumors of the oral cavity in an Indian community. Int J Cancer 2005; 113: 946-950. http: //dx.doi.org/10.1002/ijc.20664

[24] TACHEZY R, KLOZAR J, SALAKOVA M, SMITH E, TUREK L et al. HPV and other risk factors of oral cavity/oropharyngeal cancer in the Czech Republic. Oral Diseases 2005; 11: 181-185. http: //dx.doi.org/10.1111/j.1601-0825.2005.01112.x

[25] SLEBOS RJ, YI Y, ELY K, CARTER J, EVJEN A et al. Gene expression differences associated with human papillomavirus status in head and neck squamous cell carcinomas. Clin Cancer Res 2006; 12: 701-709. http://dx.doi.org/10.1158/1078-0432. CCR-05-2017

[25] EL-MOFTY SK, PATL S.: Human papillomavirus (HPV)-related oropharyngeal nonkeratinizing squamous cell carcinoma: characterization of a distinct phenotype. Oral Surg Oral Med Oral Pathol Oral Radiol Endod 2006; 101: 339-345. http: //dx.doi.org/10.1016/j.tripleo.2005.08.001

[26] WEINBERGER PM, YU Z, HAFFTY BG, KOWALSKI D, HARIGOPAL $M$ et al. Molecular classification identifies a subset of human papillomavirus-associated oropharyngeal cancers with favourable prognosis. J Clin Oncol 2006; 24: 736-747. http: //dx.doi.org/10.1200/JCO.2004.00.3335

[27] LUOCW, ROAN CH, LIU CJ. Human papilloma viruses in oral squamous cell carcinoma and precancerous lesions detected by
PCR-based gene-chip array. Int J Oral Maxillofac Surg 2007; 36: 153-158. http: //dx.doi.org/10.1016/j.ijom.2006.09.005

[28] CHUANG AY, CHUANG TC, CHANG S, ZHOU S, BEGUM $S$ et al. Presence of HPV DNA in convalescent salivary rinses is an adverse prognostic marker in head and neck squamous cell carcinoma. Oral Oncol 2008; 44: 915-919. http: //dx.doi. org/10.1016/j.oraloncology.2008.01.001

[29] KLOZAR J, KRATOCHVIL V, SALAKOVA M, SMAHELOVA J, VESELA E et al.: HPV status and regional metastasis in the prognosis of oral and oropharyngeal cancer. Eur Arch Otorhinolaryngol 2008; 265(Suppl. 1): S75-S82. http: //dx.doi. org/10.1007/s00405-007-0557-9

[30] LOHAVANICHBUTR P, HOUCK J, FAN W, YUEH B, MENDEZ E et al. Genomewide gene expression profiles of HPV-positive and HPV-negative oropharyngeal cancer: potential implications for treatment choices. Arch Otolaryngol Head Neck Surg 2009; 135: 180-188. http: //dx.doi. org/10.1001/archoto.2008.540

[31] GUDLEVICIENE Z, SMAILYTE G, MICKONAS A, PIKELIS A. Prevalence of human papillomavirus and other risk factors in Lithuanian patients with head and neck cancer. Oncology 2009; 76: 205-208. http: //dx.doi.org/10.1159/000201573

[32] WEINBERGER PM, YU Z, KOUNTOURAKIS P, SASAKI C, HAFFTY BG et al. Defining molecular phenotypes of human papillomavirus-associated oropharyngeal squamous cell carcinoma: validation of three class hypothesis. Otolaryngol Head Neck Surg 2009; 141: 382-389. http: //dx.doi.org/10.1016/ j.otohns.2009.04.014

[33] SHI W, KATO H, PEREZ-ORDONEZ B, PINTILIE M, HUANG $S$ et al. Comparative prognostic value of HPV16 E6 mRNA compared with in situ hybridization for human oropharyngeal squamous carcinoma. J Clin Oncol 2009; 27: 6213-6221. http: //dx.doi.org/10.1200/JCO.2009.23.1670

[34] STRAETMANS JM, OLTHOF N, MOOREN JJ, DE JONG J, SPEEL EJ et al. Human papillomavirus reduces the prognostic value of nodal involvement in tonsillar squamous cell carcinomas. Laryngoscope 2009; 119: 1951-1957. http: //dx.doi. org/10.1002/lary.20593

[35] TACHEZY R, KLOZAR J, RUBENSTEIN L, SMITH E, SALAKOVA $M$ et al.: Demographic and risk factors in patiens with head and neck tumors. J Med Virol 2009; 81: 878-887. http: //dx.doi.org/10.1002/jmv.21470

[36] ATTNER P, DU J, NASMAN A, HAMMARSTEDT L, RAMQVIST T. The role of human papillomavirus in the increased incidence of base of tongue cancer. Int J Cancer 2010; 126: 2879-2884.

[37] BENNETT KL, LEE W, LAMARRE E, ZHANG X, SETH $\mathrm{R}$ et al. HPV status-independent association of alcohol and tobacco exposure or prior radiation therapy with promoter methylation of FUSSEL18, EBF3, IRX1, and SEPT9, but not SLC5A8, in head and neck squamous cell carcinomas. Genes Chromosomes Cancer 2010; 49: 319-326.

[38] HOFFMANN M, IHLOFF AS, GOROUGH T, WEISSE JB, FAZEL A. p16(INK4a) overexpression predicts translational active human papillomavirus infection in tonsillar cancer. Int J Cancer 2010; 127: 1595-1602. http: //dx.doi.org/10.1002/ ijc. 25174 
[39] LEWIS JS, THORSTAD WL, CHERNOCK RD, HAUGHEY $\mathrm{BH}, \mathrm{YIP}$ JH et al.: p16 positive oropharyngeal squamous cell carcinoma: an entity with a favourable prognosis regardless of tumor HPV status. Am J Surg Pathol 2010; 34: 1088-1096. http: //dx.doi.org/10.1097/PAS.0b013e3181e84652

[40] ROTNAGLOVA E, TACHEZY R, SALAKOVA M, PROCHAZKA B, KOSLABOVA E et al.: HPV involvement in tonsillar cancer: prognostic significance and clinically relevant markers. Int J Cancer 2011; 129: 101-110. http: //dx.doi. org/10.1002/ijc.25889

[41] KUMARASWAMY KL, VIDHYA M.: Human papilloma virus and oral infections: an update. J Cancer Res Ther 2011; 7: 120-127. http: //dx.doi.org/10.4103/0973-1482.82915

[42] SWARTZ SM, DALING JR, DOODY DR, WIPF GC, CARTER $J$ et al. Oral cancer risk in relation to sexual history and evidence of human papillomavirus infection. J Natl Cancer Inst 1998; 90: 1626-1636. http: //dx.doi.org/10.1093/jnci/ $\underline{90.21 .1626}$
[43] ZARAVINOS A, MAMMAS IN, SOURVINOS G, SPANDIDOS DA. Molecular detection methods of human papillomavirus (HPV). Int J Biol Markers 2009; 24: 215 222.

[44] VON KNEBEL DOEBERITZ. New markers for cervical dysplasia to visualise the genomic chaos created by aberrant oncogenic papillomavirus infection. Eur J Cancer 2002; 38: 2229-2242. http: //dx.doi.org/10.1016/S0959-8049(02)00462$\underline{8}$

[45] LASSEN P, ERIKSEN JG, HAMILTON-DUTOIT S, TRAMM S, ALSNER J et al. Effect of HPV-associated p16INK4a expression on response to radiotherapy and survival in squamous cell carcinoma of the head and neck. J Clin Oncol 2009; 27: 1992-1998.

[48] FISHER CA, ZLOBEC I, GREEN E, PROBST S, STORCK C et al. Is the improved prognosis of $\mathrm{p} 16$ positive oropharyngeal squamous cell carcinoma dependent of the treatment modality? Int J Cancer 2010; 126: 1256-1262. 